\title{
Pengembangan Permukiman Nelayan Kingking dan Karangsari Tuban Melalui Pendekatan Urban Assemblage
}

\author{
Tyas Santri \\ Program Studi Arsitektur, Fakultas Teknik, Universitas Langlangbuana Bandung, Indonesia \\ tyassantriarch@gmail.com
}

\begin{abstract}
ABSTRAK
Indonesia negara kepulauan dengan lautan lebih besar dari pada daratan, maka tidak dipungkiri di Indonesia banyak permukiman nelayan. Seringkali permukiman nelayan di Indonesia termarjinalkan dalam pengembangan industri maritim dan jasa, bahkan menjadi korban aktivitas pemanfaatan wilayah pesisir oleh swasta yang bergerak bidang pariwisata, industri dan jasa. Masyarakat permukiman nelayan kurang mendapatkan dampak positif dari pengembangan tersebut, maka dari itu ini bertujuan agar masyarakat permukiman nelayan dapat mendapatkan dapak positif dari pengembangan wilayah disekitarnya. Penelitian ini mengambil studi kasus pada permukiman nelayan Kingking dan Karangsari di kabupaten Tuban, Jawa Timur. Pendekatan yang digunakan dalam penelitian adalah pendekatan urban assemblage untuk mengungkap rajutan sosial-budaya sebagai kekuatan budaya yang membentuk keberlangsungan tempat tersebut. Pedekatan urban assemblage akan didukung dengan metode penelusuran yang selanjutnya dianalisis secara deskriptif kualitatif. Penelusuran dilakukan melalui tinjauan literatur dan survei lapangan. Penelitian ini menyajikan hasil berupa pemetaan dari rajutan antara budaya, social, ekonomi sebagai kekuatan budaya pemukiman nelayan Kingking dan Karangsari dengan kawasan wisata yang ada di sekitarnya. Hasil kajian ini dapat menjadi bahan pertimbangan pemerintah maupun masyarakat setempat dalam merencanakan pengembangan kawasan pesisir atau pemukiman nelayan menjadi destinasi wisata.
\end{abstract}

Kata kunci: urban assemblage, permukiman nelayan, wisata

\section{ABSTRACT}

Indonesia is an archipelago country with a sea larger than the mainland, so it is undeniable that in Indonesia there are many fisherman settlements. Often fishermen settlements in Indonesia are marginalized in the development of maritime and service industries and even become victims of the activities of the utilization of coastal areas by the private sector engaged in tourism, industry, and services. The fisherman settlement community is not getting a positive impact from the development, therefore this study aims so that the fisherman settlement community can get a positive impact from the development of the surrounding area. This research takes a case study in the fisherman settlements of Kingking and Karangsari in Tuban Regency, East Java. The approach used in this research is the urban assemblage approach to reveal socio-cultural knits as a cultural force that shapes the sustainability of the place. The urban assemblage approach will be supported by search methods which will then be analyzed descriptively qualitatively. The search was carried out through literature review and field surveys. This research presents the results in the form of a mapping of knits between culture, social, the economy as the cultural strength of the Kingking and Karangsari fisherman settlements with the surrounding tourist areas. The results of this study can be considered by the government and local communities in planning the development of coastal areas or fisherman settlements into tourist destinations.

Keywords: urban assemblage, fisherman settlements, tourism 


\section{Pendahuluan}

Assemblage merupakan pendekatan yang dalam Bahasa Indonesia sering diterjemahkan "rajutan". Pendekatan urban assemblage menjadi salah satu arternatif dalam mengungkap fenomena yang terjadi dalam perkotaan atau suatu kawasan, salah satunya mengungkap rajutan antar suatu kawasan dengan kawasan lainya yang memiliki potensi lokal/ potensi wisata untuk saling mendukung dan meningkatkan ekonomi masyarakatnya. Dimana pengembangan sektor ekonomi lokal dan sumber daya alam merupakan salah satu upaya untuk meningkatkan perekonomian daerah. Demi mendukung peningkatan ekonomi, daerah harus mengupayakan dengan menggalih potensi lokal sebagai salah satu upaya untuk mengbangkan ekonomi lokal dan sumber daya alam adalah melalui pariwisata. Potensi suatu daerah dapat berupa masyarakat (people), alam (nature) dan budaya (culture) yang ketiganya dapat disinergikan agar kedepannya dapat bekerja secara bersamaan dalam memberikan dampak positif peningkatan pengembangan ekonomi lokal dan sumberdaya alam untuk pembangunan pariwisata.

Kabupaten Tuban terletak di jalur pantai utara mempunyai peluang besar dalam mengembangkan potensi wisatanya memalalui kekayaan budaya dan sumber daya alamnya. Potensi budaya Kabupaten Tuban tidak hanya bersifat kultus sosial, tetapi juga banyak yang mengandung nilai sosial, budaya, ekonomi yang dapat digunakan sebagai modal utama terhadap arah pembangunan pariwisata. Dalam kajian ini salah satu potensi budaya yang dimiliki oleh kabupaten Tuban yang akan digali adalah potensi wilayah pesisirnya dengan objek studi pemukiman nelayan Kingking dan Karangsari

Permasalahan dalam kajian ini adalah permukiman nelayan yang kurang rapi dan berbau amis namun memiliki potensi lokal yang dapat di kembangkan sehingga memunculkan sebuah pertanyaan "Bagaimana permukiman nelayan Kingking dan Karangsari yang berada di pusat kota dan di kelilingi oleh destinasi wisata dapat menjalin assemble dengan destinasi wisata di sekitarnya sehingga meningkatkan daya tarik permukiman nelayan Kingking dan Karangsari itu sendiri. Tujuan kajian ini adalah menelusuri potensi lokal (sosial, ekonomi, budaya) yang dimiliki permukiman nelayan Kingking dan Karangsari yang belum terkekspose kemudian merumuskan strategi pengkoneksian antar potensi lokal dengan kawasan wisata di sekitarnya dengan pendekatan Urban Assemblage. Dengan permukiman nelayan menjadi destinasi wisata secara tidak langsung akan memberikan dapak peningkatan ekonomi dan sosial pemukiman tersebut. Potensi ekonomi dan sosial budaya sebagai genius loci yang secara tidak sadar dimiliki oleh pemukiman nelayan Kingking dan Karangsari antara lain aktifitas penjualan ikan yang berlansung di depan permukiman yaitu di sepanjang jalan Panglima Sudirman, aktifitas berlayar dan lain sebagainya. Potensi-potensi tersebut jika di berikan perhatian lebih akan menjadi kekuatan fisik place dan space yang dapat menjalin assemble dengan destinasi wisata di sekitarnya.

Urgensi pendekatan Urban Assemblage dalam kajian ini adalah upaya peningkatan nilai potensi permukiman nelayan Kingking dan Karangsari diberdayakan secara optimal maka dibutuhkan penataan yang mencakup pengelolaan dalam pengembangan permukiman nelayan Kingking dan Karangsari melalui stategi assemblage dengan destinasi wisata yang sudah ada di sekitarnya. Maka penelitian ini mengujicobakan konsep assemblage untuk melacak bagaimana potensi dan kekuatan budaya yang ada di permukiman nelayan Kingking dan Karangsari bekerja dalam praktik penciptaan tempat (place-making) sehari-hari dan dapat menjalin rajutan, integrasi dengan place (tempat wisata) yang sudah ada di sekitarnya. Dengan terjalinnya assemble potensi ini menjadi dibutuhkan untuk memudahkan pergerakan wisatawan serta penduduk setempat dalam 
mengakses potensi dan informasi kawasan yang dapat diangkat sebagai bagian dari atraksi wisata.

\section{Bahan dan Metode}

\subsection{Tinjauan Pustaka}

2.1.1 Teori Assemblage

Pendekatan assemblage menjadi sebuah pendekatan yang digunakan untuk mengungkap fenomena yang terjadi dalam perkotaan. Pendekatan ini dianggap mampu melihat potensi nyata yang ada dalam perkotaan yang sering tidak terungkap. Konsepkonsep tentang "habitus dan field" dari Bourdieu (1977), "rhizome" dari Deleuze (1980), "produksi ruang" dari Lefebvre (1991), dan "jejaring-aktor" (Actor-Network Theory/ ANT) dari Latour (2005), "place as assemblage" dari Dovey (2010) merupakan pemikiran yang menjadi dasar munculnya konsep "assemblage" dalam melihat relasi antara manusia/masyarakat dan lingkungan binaan. Dan suatu lingkungan perkotaaan, yang tersusun melalui konfigurasi sosial, budaya dan arsitekturalnya (potensi yang ada), merupakan bentuk assemblage yang paling merepresentasikan suatu masyarakat tertentu. Suatu tempat (place) bisa terbentuk dengan ditandai adanya bentuk fisik, aktivitas, dan citra. Hidupnya suatu tempat ditandai oleh kecerdasan lokal, "Genius loci", sebagai "ruh yang menjaga tempat" (Norberg-Schultz, 1991:5), dan "ruh" ini berperan penting dalam hidup dan matinya sebuah tempat atau kawasan.

\subsubsection{Permukiman Nelayan}

Pemukiman nelayan berada di pesisir pantai. Pemukiman nelayan merupakan basic kawasan yang menampung seluruh kegiatan para nelayan dalam kehidupan sehari-hari dan kegiatan ekonominya (R. Suprihardjo dan D. Rahmaati, 2014). Dalam Refshauge (2003) beberapa permukiman pantai dapat diklasifikasikan antara lain Kampung Kota Pantai (Coastal Towns), Kota Pantai (Coastal Cities), Daerah Berpusat di Pantai (Inland Coastal Centres), Desa Pantai (Coastal Villages), dan Permukiman Berpusat di Pantai (New Coastal Settlements). Apabila suatu kawasan pesisir dibangun untuk destinasi wisata, biasanya fasilitas-fasilitas pendukung lainnya juga berkembang pesat (Dahuri R., 2001).

Perencanaan pengelolaan wilayah pesisir diatur dalam Peraturan Menteri Kelautan dan Perikanan No. 16/2008, bahwa perencanaan pengelolaan wilayah pesisir merupakan suatu proses penyusunan tahapan-tahapan kegiatan yang melibatkan berbagai unsur kepentingan dalam pemanfaatan dan pengalokasian sumber daya pesisir demi kesejahteraan sosial masyarakat. Pengembangan kepariwisataan yang melibatkan masyarakat mengandung pengertian bahwa, pembangunan kepariwisataan harus mampu mensejahterahkan masyarakat dengan mendorong pemberdayaan masyarakat agar mampu berperan aktif untuk mendapatkan manfaat sebesar-besarnya, dengan mengelola sumberdaya dan objek wisata pelestarian warisan budaya dan alam (Ardika, 2002).

\subsubsection{Pengembangan Potensi Kawasan Pariwisata}

Pengembangan potensi suatu kawasan menjadi destinasi wisata merupakan salah satu upaya dan trobosan pembangunan bidang pariwisata suatu daerah dengan tujuan meningkatkan pendapatan daerah dan Negara. Pariwisata selain sebagai peningkatkan ekonomi juga untuk perdamaian, keamanan dan pelestarian lingkungan (D Aulianti dan M Massadun, 2016). Menurut Nyoman S. Pendit potensi wisata bisa berupa suasana, kejadian, benda, jasa, sumber daya alam yang beraneka ragam dari aspek fisik dan hayati, serta 
kekayaan budaya manusia yang dapat dikembangakan. Potensi wisata di dukung oleh sumber daya pariwisata. Menurut Chafid Fandeli sumber daya pariwisata ini merupakan unsur-unsur lingkungan alam atau yang telah diubah oleh manusia yang dapat memenuhi keinginan wisatawan. Budaya dalam pengembangan pariwisata dianggap sebagai modal (Ooi, 2002). Robbins (2000 dalam Ooi, 2002) berpendapat bahwa modal budaya merupakan suatu latar belakang sosial budaya individu yang akan terus berkembang melalui sistem pendidikan. Sementara itu, menurut Zukin (1990 dalam Ooi, 2002) modal budaya mengacu pada beberapa jenis modal yang diinvestasikan untuk industri budaya, mencakup film, makanan, majalah, arsitektur, dan pariwisata budaya. Gunn (1994) mengemukakan bahwa suatu kawasan wisata yang baik dan berhasil secara optimal didasarkan pada empat aspek, antara lain: mempertahankan kelestarian lingkungannya, menjamin kepuasan pengunjung, meningkatkan keterpaduan dan kesatuan pembangunan masyarakat di sekitar kawasan dan zone penataannya, meningkatkan kesejahteraan masyarakat di kawasan tersebut. Keterkaitan antara budaya dan pariwisata yang terus menguat menjadikan budaya sebagai faktor penggerak perekonomian melalui penciptaan lapangan kerja dan peningkatan pendapatan (Richards, 2001 dalam Richards dan Wilson, 2007).

Selain potensi budaya sebagai modal dari pengembangan pariwisata Menurut Inskeep (1991) yang di peroleh dari berbagai macam literatur adapun berbagai macam komponen pariwisata yang mendukung pengembangan wisata suatu daerah antara lain adalah:

a. Kegiatan dan atraksi-atraksi wisata: segala sesuatu yang terkait lingkungan alami, kebudayan, kekhasan dan kegiatan lain yang menarik wisatawan untuk berkunjung. Dalam kegiatan dan atraksi wisata ini potensi budaya dan alam suatu daerah menjadi hal yang sangat penting

b. Akomodasi: berperan penting dalam pengempangan pariwisata, dimana akomodasi merupakan fasilitas yang dibutuhkan oleh wisatawan seperti tempat menginap.

c. Fasilitasal pelayanan wisata: fasiltas yang harus ada di sekitar lokasi wisata dan dibutuhkan dalam perencannaan berwisata seperti tour and travel, tempat makan, toko souvenir, toko-toko lainnya, tempat menarik uang (bank atau ATM), tempat penukaran uang, information center, tempat pelayanan pribadi (misal salon kecantikan), fasilitas kesehatan, fasilitas keamanan umum (seperti fasilitas keamanan/kantor polisi dan pemadam kebakaran).

d. Fasilitas pelayanan transportasi: akses yang tersedia dan jenis transportasi yang tersdia untuk menuju lokasi wisata.

e. Infrastruktur: yang harus dipenuhi saat pengembangan pariwisata antara lain penyediaan air bersih, listrik, drainase, saluran air kotor, dan telekomunikasi

f. Elemen kelembagaan: merupakan kelembagaan untuk mengelola kegiatan wisata seperti perencanaan tenaga kerja, program pendidikan dan pelatihan, menyususn strategi marketing dan program promosi, peraturan dan perundangundangan yang terkait dengan pariwisata dan sebagainya.

Komponen-komponen pariwisata diatas perlu di dukung oleh peran serta masyarakat dan pemerintah setempat. Bagaimana masyarakat lokal dapat diberdayakan dan diikut sertakan dalam aktivitas kegiatan pariwisata itu sendiri baik dalam rangka menjaga kondisi lingkungan dimana obyek wisata, penyelenggaraan atraksi-atraksi wisata dan memperoleh kemanfaatan dari kegiatan pariwisata. Selain mengikut sertakan masyarakat setempat dalam pengembangan pariwisata, perintah setempat juga turut berparsisipasi dalam mengembangkan aspek-aspek yang mempengaruhi pengembangan 
pariwisata antara lain dalam fasiliitas pelayanan wisata, fasilitas pelayanan trasportasi, fasilitas infrastruktur dan kelembagaan.

\subsection{Metodologi Penelitian}

Metode yang digunakan dalam kajian ini adalah deskriptif-kualitatif dengan penyelidikan secara deskriptif yang dilakukan dengan teknik survey. Survey dilakukan adalah melakukan kajian kepustakaan dengan mengumpulkan, mempelajari semua pustaka yang terkait dengan judul kajian, baik secara langsung maupun tidak langsung, serta melakukan survey lapangan ke objek studi dan mengadakan wawancara dengan beberapa narasumber. Analisis tentang pengembangan permukiman nelayan melalui pendekatan urban assemblage antara permukiman nelayan kingking dan karangsari dengan kawasan wisata disekitarnya dilakukan dengan telaah terhadap rajutan antara budaya, sosial, ekonomi sebagai kekuatan dan modal pemukiman nelayan Kingking dan Karangsari untuk menjadi lokasi wisata.

Wilayah studi kajian ini adalah pemukiman nelayah kelurahan Kingking yang berada di sepanjang tepi jalan Panglima Sudirman ditambahkan wilayah permukiman nelayan Karangsari yang berada di sebelah utara jalan Panglima Sudirman yaitu pemukiman nelayan yang langsung berada di tepi pantai utara Tuban.

\section{Hasil dan Diskusi}

\subsection{Karakteristik Wilayah Kajian}

Permukiman nelayan Kingking dan Karangsari merupakan salah satu wilayah pesisir di Kabupaten Tuban yang mayoritas penduduknya adalah bermatapencaharian sebagai nelayan dan pedagang. Kondisi sosial budaya di permukiman ini masih cukup bagus dengan adanya kebiasaan gotong royong dengan tetangga. Penduduk nelayan Kingking dan Karangsari mayoritas beragama Islam, selain itu di permukiman ini masih memegang sistem kepercayaan adat seperti rutinitas sedekah laut. Karakteristik hunian di wilayah kajian yaitu rumah saling berhadap hadapan dan berhimpitan dengan tetangga, adapun sebagian ruangan yang ada di hunian di jadikan warung untuk berjualan kebutuhan sehari-hari, berjualan makanan, dll., untuk beberapa rumah di bagian depan terdapat teras sedikit untuk area bencengkaram dengan tetangga. Ruang yang terbentuk antara rumah di fungsikan sebagai sirkulasi atau disebut jalan "gang". Sirkulasi "gang" di permukiman nelayan ini memiliki nama-nama ikan seperti Gang Ikan Ganas, Gang Dorang, Gang Togek, dll. Gang-gang yang ada di permukiman ini selain sebagai sirkulasi jalan juga dimanfaatkan oleh penduiduk untuk parkir kendaraan, aktifitas membersihkan dan mengolah ikan hasil tangkapan untuk di jual atau di perdagangkan, area bermain anakanak. Naungan teras hunian yang berada di pinggir jalan Panglima Sudirman sampai pada area pedestrian jalan selain itu juga masih terdapat bangunan lama. Area tepi laut menjadi area belakang rumah dan menjadi area berlabuhnya perahu nelayan di saat tidak berlayar dan area ini terlihat kotor karena banyak sampah yang dibuang.
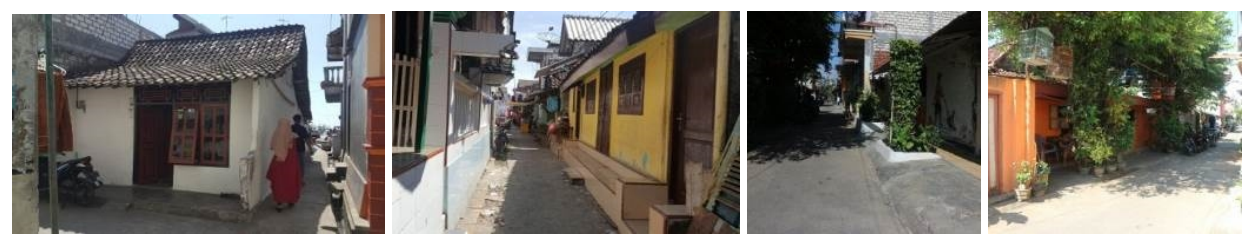

Gambar 1. Karakteristik Hunian di Dalam Gang (di Dalam Permukiman yang Belum Menjadi Kampung Warna) 

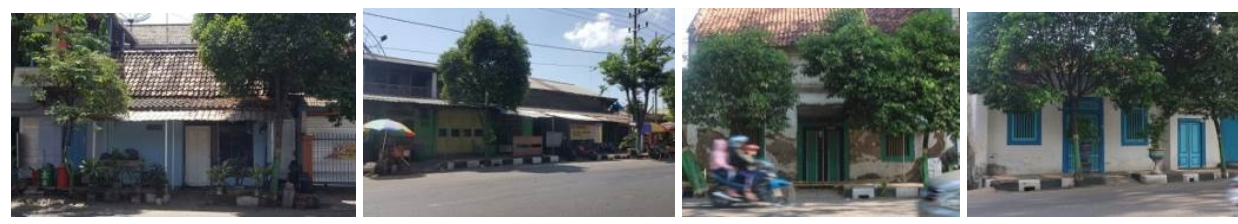

Gambar 2. Karakteristik Hunian di Pinggir Jalan Panglima Sudirman
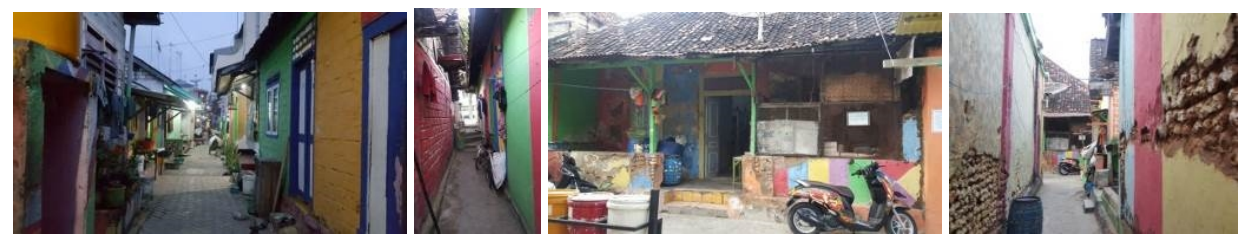

Gambar 3. Karakteristik Hunian di Dalam Gang (di Dalam Permukiman yang Sudah Menjadi Kampung Warna)
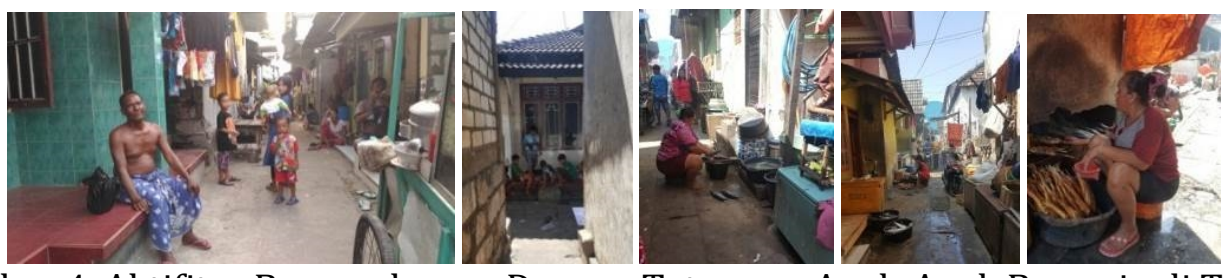

Gambar 4. Aktifitas Bercengkrama Dengan Tetangga, Anak-Anak Bermain di Teras

Rumah dan Sirkulasi Gang, dan Aktifitas Membersihkan-Mengolah Ikan Hasil

Tangkapan di Gang
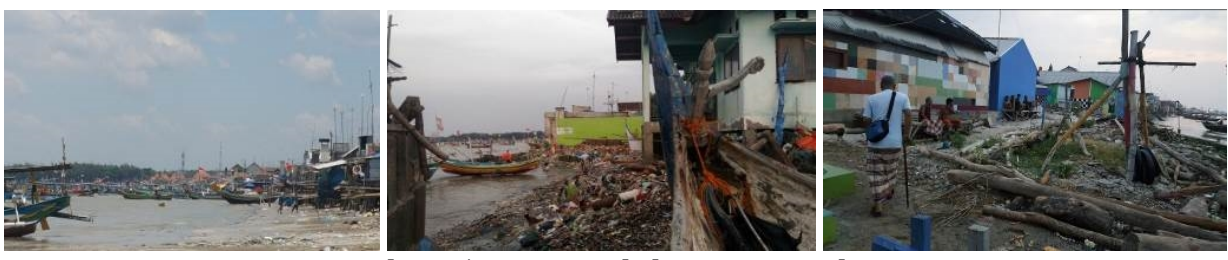

Gambar 5. Area Belakang Rumah

\subsection{Pengembangan Permukiman Nelayan}

Pengembangan permukiman nelayan melalui pendekatan urban assemblage dilakukan dengan simulasi desain perancangan kawasan yang menunjukan adanya fenomena, potensi atau karakter kawasan permukiman nelayan "Kingking" dengan kawasan wisata disekitarnya. Adapun potensi wilayah kajian dilihat dari berbagai macam komponen pariwisata yang mendukung pengembangan wisata suatu daerah antara lain adalah:

a. Kegiatan atraksi-atraksi wisata

Kegiatan-kegiatan di permukiman nelayan wilayah kajian yang dapat di jadikan sebagai atraksi-atraksi wisata antara lain kegiatan mebersihakan dan mengolah ikan hasil tangkapan (gambar 4), kegiatan meperdaganggakan hasil tangkapan ikan segar di Plaza Ikan Tuban dan ikan asap di sepanjang jalan Panglima Sudirman (gambar 6), kegiatan saat nelayan melabuhkan perahunya (gambar 6), kegiatan sedekah laut selain itu nelayan di wilayah kajian ini memiliki kebiasaan bencengkrama sambil minum legen atau tuak lontar khas Kabupaten Tuban (gambar 6). 


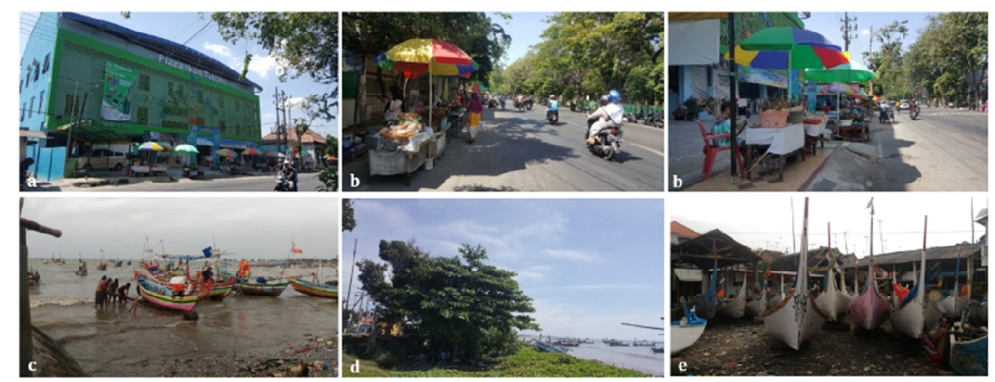

Gambar 6. a) Plaza Ikan Tuban, b) Berjualan Ikan Asap di Sepanjang Jalan Panglima Sudirman, c) Nelayan Melabuhkan Perahu, d) Bercengkrama Sambil Minum Legen Atau Tuak Lontar, e) Area Terbuka di Lokasi Kajian Untuk Menyimpan Perahu yang Sedang Tidak Digunakan Berlayar

b. Akomodasi

Akomodasi berupa penginapan mudah di dapatkan karena lokasi kampung nelayan Kingking dan Karangsari terletak pusat kota dan di pinggir jalan Panglima Sudirman yang merupakan jalan nasional selain itu kampung nelayan Kingking dan Karangsari terletak di dekat beberapa lokasi tujuan wisata.
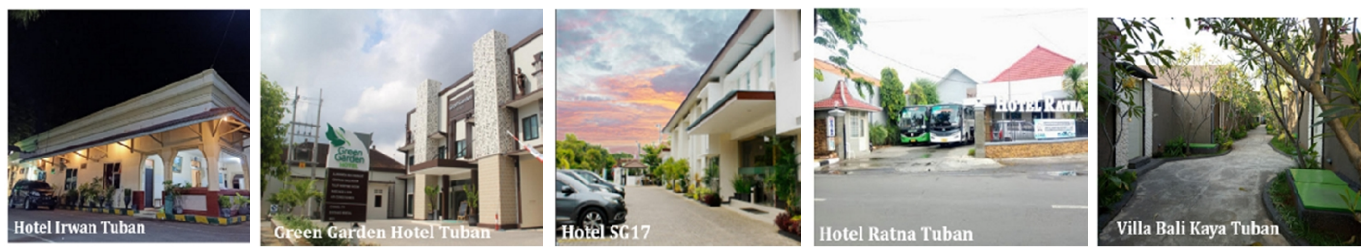

Gambar 7. Beberapa Penginapan Terdekat Dengan Lokasi Kajian

(Sumber: Diolah dari Google Maps, 2020)

c. Fasilitasal pelayanan wisata

Fasilitas pelayanan wisata yang sudah ada dilokasi kajian adalah tempat makan, untuk fasilitas lainnya seperti tour and travel, toko souvenir, tempat menarik uang (bank atau ATM), tempat penukaran uang, information center, tempat pelayanan pribadi (misalnya salon kecantikan), fasilitas kesehatan, fasilitas keamanan umum terletak di sekitar lokasi kajian radius $\pm 2 \mathrm{~km}$.

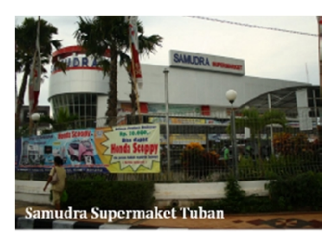

Gambar 8. Beberapa Fasilitas Pelayanan Wisata Terdekat Dengan Lokasi Kajian

d. Fasilitas pelayanan transportasi

Karena lokasi terletak di pinggir jalan Panglima Sudirman yang merupakan jalan nasional yang berada di pusat Kabupaten Tuban untuk fasilitas pelayanan transportasi sangan mudah karena untu menuju lokasi kajian ini dapat menggunakan bus antar provinsi maupun kota di pulau Jawa, kendaraan pribadi kendaraan umum seperti angkota umum, becak, kendaraan online. 
e. Infrastruktur

Dari segi infrastruktur penyediaan air bersih, ketersediaan saluran drainase dan kondisi proteksi kebakaran sangat kurang.

f. Elemen kelembagaan

Elemen kelembagaan untuk mengelola kegiatan wisata di wilayah kajian memang belum seratus persen terbentuk dan terlaksana maka dari itu perlu adanya di bentuk elemen kelembagaan yang bisa di wakilkan oleh ketua rukun tetangga, ketua rukun warga, lurah dan di bantu oleh pemuda pemudi setempat. Terkait elemen kelembagaan ini juga perlu adanya fasilitas kantor yang nantinya selain sebagai kantor lembaga yang mengelola kegiata wisata juga dapat menjadi pusat informasi wisatawan yang kan berkunjung di kampung nelayan Kingking.

Assemblage, rajutan yang terjalin antara kehidupan nelayan di wilayah kajian dengan potensi wisata yang dapat dikembagkan dapat dilihat dari ruang (space) dan tempat (place) informal yang terbentuk dalam area kajian karena aktifitas sosial budaya masyarakat setempat yang terjadi secara natural setiap harinya. Ruang dan tempat tersebut antara lain adalah a) Gang permukiman yang maji ruang dan tempat aktifitas penduduk dari mengobrol, anak-anak bermain sampai mengolah hasil tangkapan ikan, b) Area berdagang ikan asap, c) Area belakang permukiman atau tepi pantai yang merupakan area para nelayan berlabuh, d) Area ruang terbuka yang sebagian manjadi tempat untuk menyimpan perahu yang sedang tidak digunakan untuk berlayar (gambar 6).

Assemblage, rajutan yang terjalin antara lokasi wisata yang berada di sekitar lokasi kajian dengan wilayah kajian terjalin adanya perbedaan karakter wilayah baik dari karakter aktifitas wisata maupun aktifitas masyarakat setempat. Perbedaan karakter aktifitas wisata inilah yang dapat menjadi daya tarik wilayah kajian menjadi lokasi wisata misalkan wisatawan yang berwisata religi ke Makam Sunan Bonang dengan karakter wilayahnya sekitar makam berupa pusat oleh-oleh khas Tuban, pemukiman Arab, area pertokoan baju milik masyarakat Arab maka wisatawan setelah selasai berwisata di kawasan Makam Sunan Bonang akan tertarik berkunjung atau berwisata ke wilayah kajian yang karakternya merupakan wilayah permukiman nelayan, baik sekedar untuk berbelanja oleh-oleh ikan segar dan ikan asap atau pun menikmati suasana kampung nelayan. Hal serupa juga akan terjadi bagi wisatawan yang berwisata di Majid Agung Tuban, Museum Kambang Putih, Alun-Alun Tuban, Pantai Boom dan Klenteng Kwangsing Bio.

Prinsip simulasi desain perancangan kawasan adalah merekomendasikan lokasi fasilitas yang belum ada, menojolkan potensi atau karakter kawasan dengan menciptakan node pada setiap segmen lokasi yang berkarakter (node menjadi ruang transisi) dan meyediakan akses serta linkage terhadap karakter lokal yang sudah terbentuk maupun belum terbentuk di kawasan permukiman nelayan Kingking dengan kawasan wisata yang sudah ada di sekitarnya seperti Pantai Boom, alun-alun kabupaten Tuban, masjid agung, makam Sunan Bonang, kampung Arab, Klenteng Kwangsing Bio, Pantai Pantura. Penambahan elemen tata hijau pada sirkulasi gang, Penataan tata informasi (signage), penanda, pencahayaan dan street furniture, Penataan fungsi-fungsi ruang terbuka yang belum teroptimalkan sebagai bagian dari wisata kawasan. Rekayasa arus lalu lintas sebagai strategi dalam membuka peluang ekonomi. 


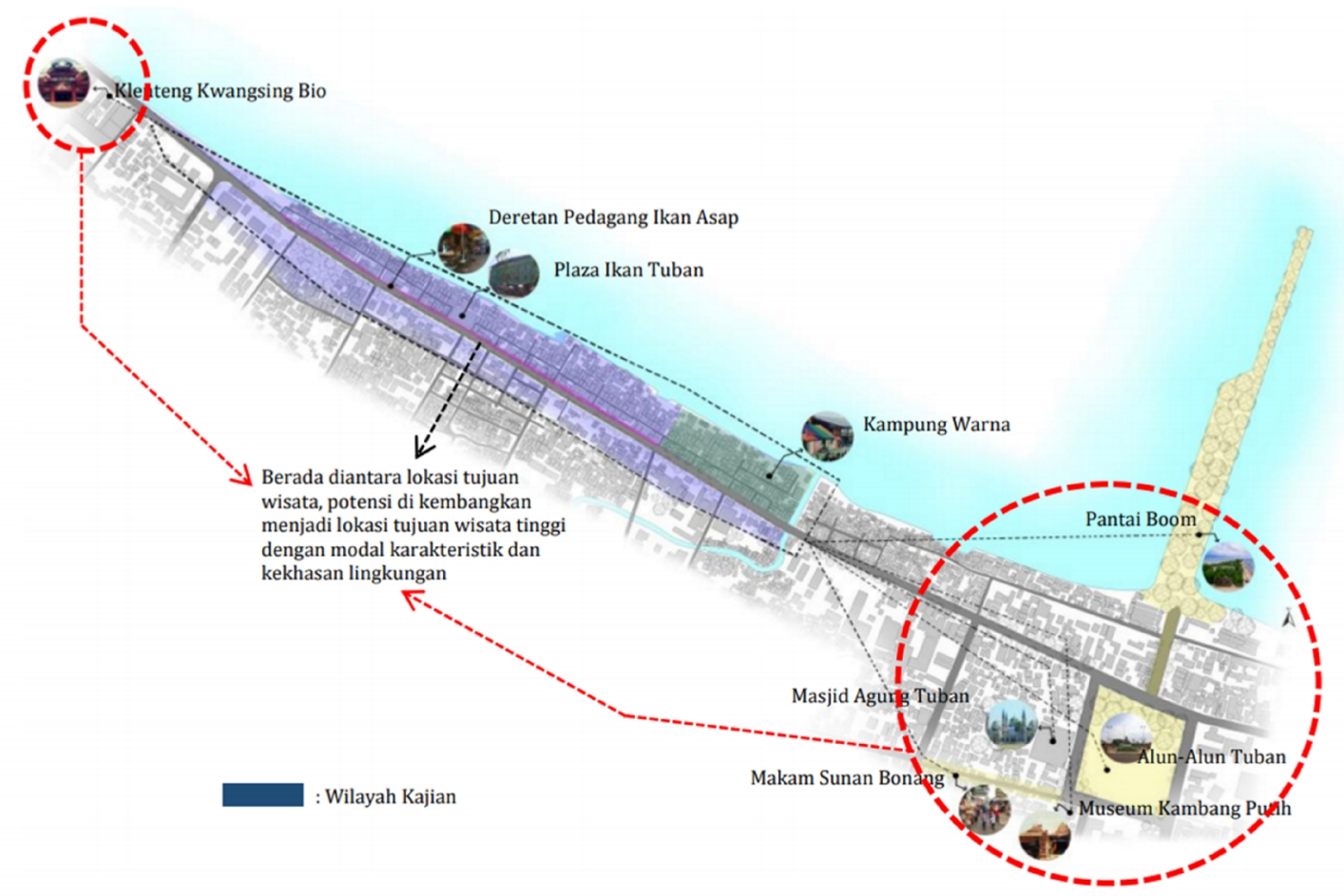

Gambar 9. Rajutan Permukiman Nelayan Wilayah Kajian Dengan Wisata di Sekitarnya (Sumber: Diolah dari Google Earth, 2019)

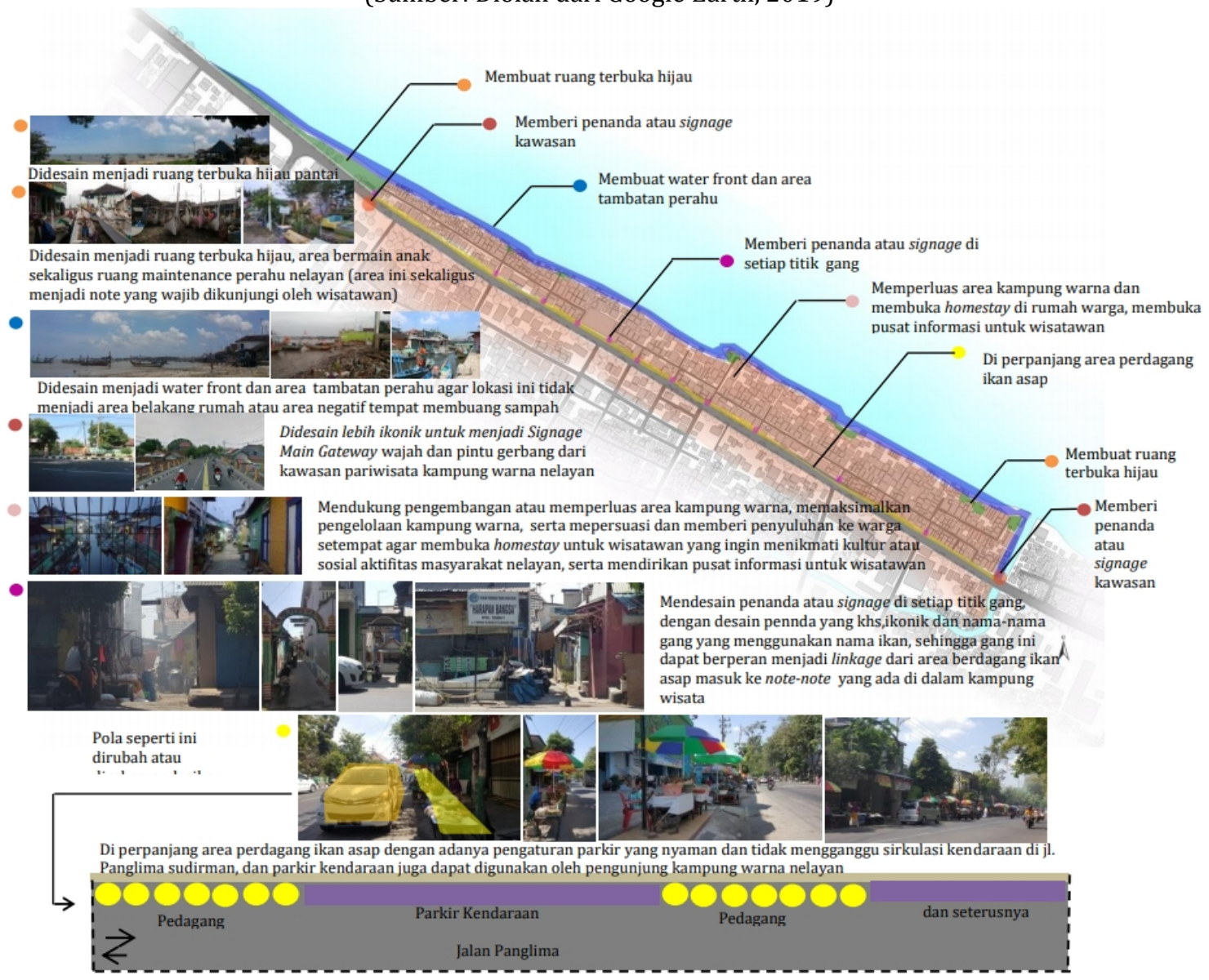

Gambar 10. Rekomendasi Prinsip Pengembangan Permukiman Nelayan Wilayah Kajian (Sumber: Diolah dari Google Earth, 2019) 


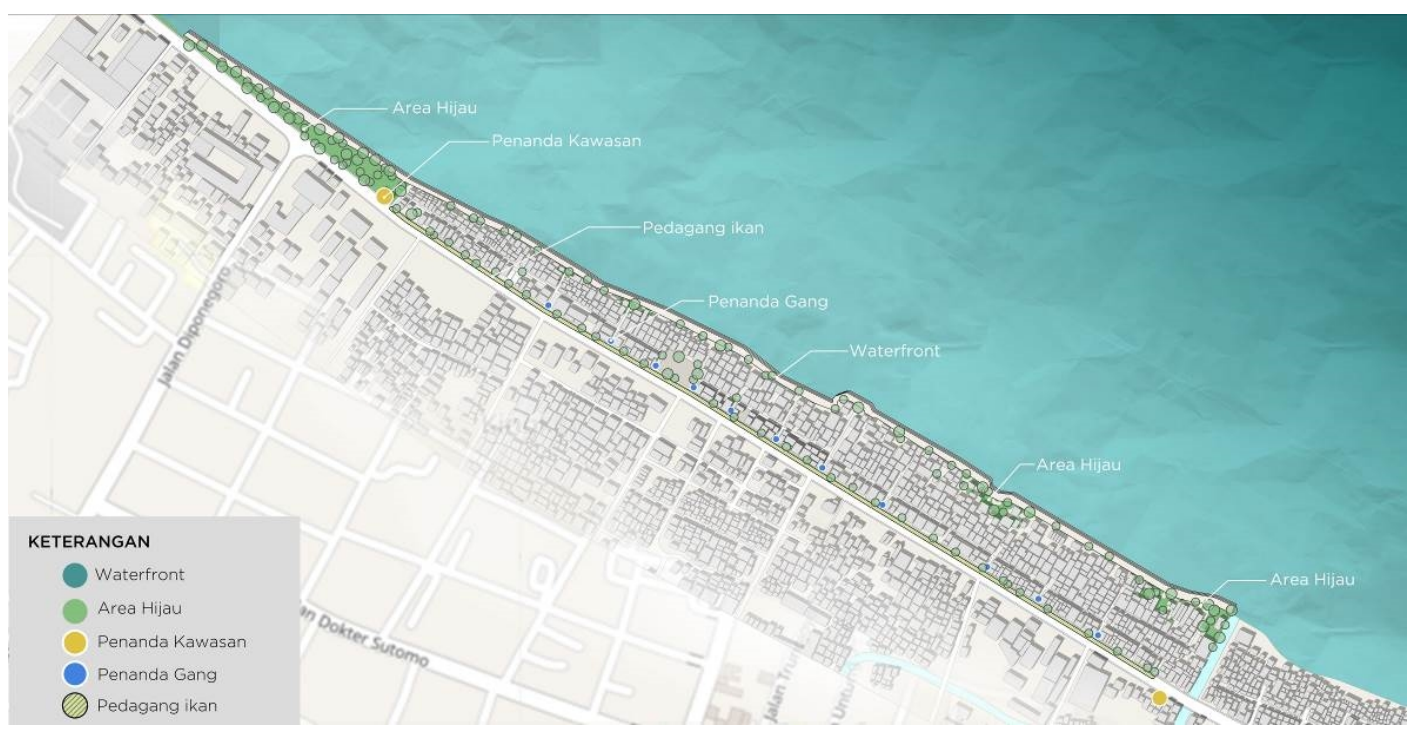

Gambar 11. Rekomendasi Siteplan Pengembangan Permukiman Nelayan Wilayah Kajian (Sumber: Diolah dari Google Maps, 2020)

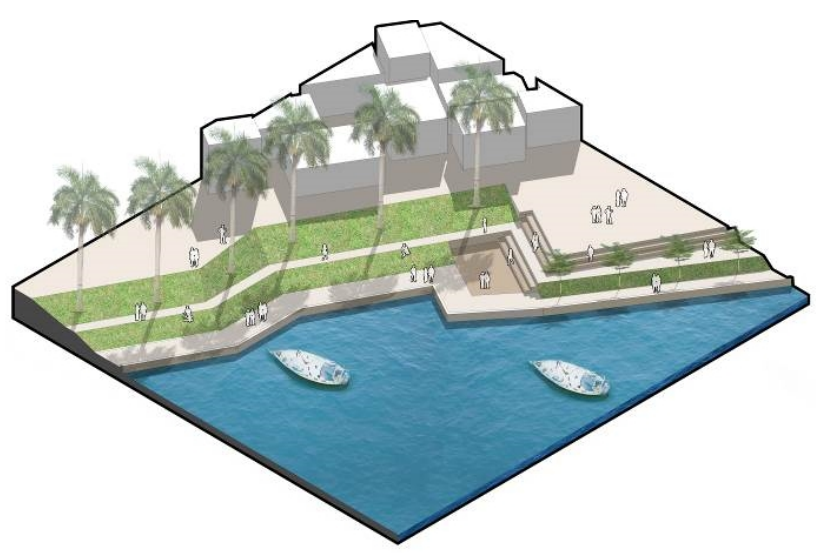

Gambar 12. Ilustrasi Area Pengembangan Belakang Rumah Menjadi Area Waterfront

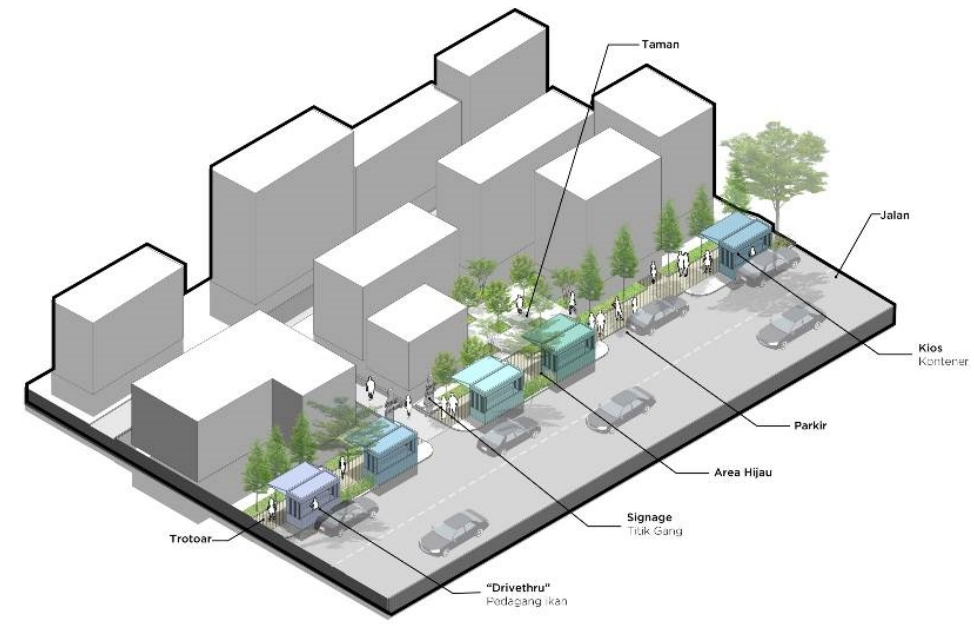

Gambar 13. Ilustrasi Area Pengembangan Berjualan Ikan Asap di Sepanjang Jalan Panglima Sudirman 


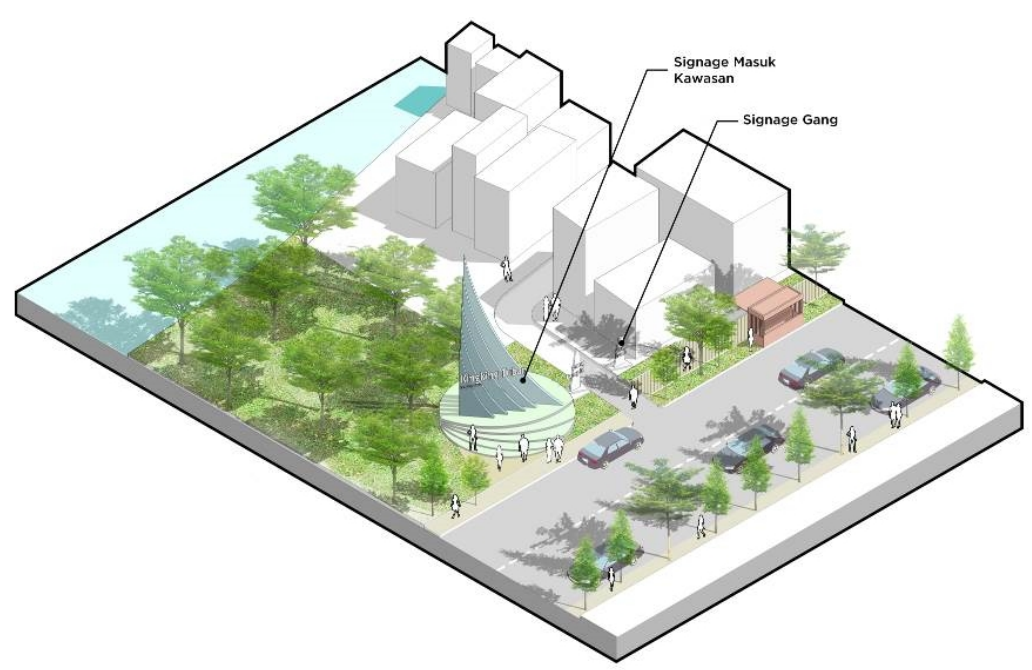

Gambar 14. Ilustrasi Signage Kawasan Sebagai Penanda Memasuki Kawasan Permukiman Nelayan

\section{Simpulan}

Berdasarkan hasil pembahasan diatas tentang pengembangan permukiman nelayan Kingking dan Karangsari melalui urban assemblage maka dapat disimpulkan bahwa rajutan antara wilayah kajian dengan lokasi wisata disekitarnya terjalin adanya perbedaan karakter wilayah baik dari karakter aktifitas wisata maupun aktifitas masyarakat sedangkan rajutan antara kehidupan nelayan di wilayah kajian dengan potensi wisata yang dapat dikembagkan dapat dilihat dari ruang (space) dan tempat (place) informal yang terbentuk dalam area kajian karena aktifitas sosial budaya, ekonomi masyarakat setempat yang terjadi secara natural setiap harinya. Kegiatan sosial, budaya, ekonomi sehari-hari yang dilakukan oleh masyarakat nelayan setempat dapat menjadi modal untuk wilayah kajian menjadi destinasi wisata, dengan mengolah kegiatan sosial, budaya, ekonomi sehari-hari menjadi kegiatan atraksi-atraksi wisata yang dapat dinikmati oleh wisatawan. Selain itu juga dengan melengkapi kawasan dengan fasilitas-fasilitas akomodasi, pelayanan wisata, pelayanan transportasi, Infrastruktur dan elemen kelembagaan.

\section{Daftar Pustaka}

Ardika, IG. (2002). Otonomi dan Pengembangan Pariwisata, diperoleh dari <http:// www.equatoronline.com.

Aulianti, D dan Massadun, M. (2016). Kajian Pengembangan Kampung Nelayan Malabero yang Terintegrasi Dengan kawasan Wisata Kebun Keling. Jurnal Teknik PWK (Perencanaan Wilayah dan Kota). Vol 5 (3). Hal 228-237.

Bourdieu, Pierre. (1997). Outline of A Theory of Practice. Cambridge University Press

Dahuri, Rokhmin, Dkk. (2001). Pengelolaan Sumberdaya Wilayah Pesisir dan Laut Secara Terpadu. Edisi ke-3 Penerbit PT. Paradnya Paramita, Jakarta.

Dovey, K. (2010). Becoming Places: Urbanism/Architecture/Identity/Power. London and New York, UK \& US: Routledge.

Guattari, Deleuze. (1980). A Thousand Plateaus: Capital and Schizophrenia. University of Minnesota Press. London.

Gunn, Clare. (1994), A Tourism Planning, Basics, Consepts, Case, Elsevier Science LTD

Gunn, Clare A., and Var, Turgut. (2002). Tourism Planning: Basic Concepts, Cases, Taylor \& Francis Books, New York, NY. 
Inskeep, E. (1991). Tourism planning: an integrated and sustainable development approach. Van Nostrand Reinhold.

Ismariandi, R. Setijanti, P. Ariastita,PG. (2010). Konsep Pengembangan Kampung Nelayan pasar Bengkulu Sebagai kawasan Wisata. Seminar Nasional perumahan permukiman dalam pembangunan Kota. Jurusan Arsitektur ITS.

Koswara, Arwi Yudhi, Dkk. (2018). Tipologi Kawasan Permukiman Jumuh di Pesisir Kabupaten Tuban, Studi Kasus: Kelurahan Kingking. Jurnal Kota Layak Huni Urbanisasi dan Pengembangan Perkotaan.

Latour, Bruno. (2005). Reassembling the Social - An Introduction to Actor-Network-Theory. Oxford University Press.

Lefebvre, Henri. (1991). The Production of Space. Oxford, OX, UK; Cambridge, Mass., USA: Blackwell.

Norberg-Schulz, C. (1991). Genius Loci: Towards a Phenomenology of Architecture. Rizzoli, New York.

Ooi, Can-Seng. (2002). Cultural Tourism \& Tourism Cultures. Denmark: Copenhagen Business School Press.

Refshauge, A. Dr. (2003). Coastal Design Guidelines for New South Wales. The Departement of NSW Goverenment. https://www.planning.nsw.gov.au/ /media /Files/DPE/Guidelines/coastal-design-guidelines-for-nsw-2003-02.ashx

Richard, Greg dan Wilson, Julie. (2007). Tourism, Creativity, and Development. Oxon: Routledge.

Santri, T. (2017). Tipologi Rumah desa Wisata di Dusun Ngluwuk Desa Batik Gedhog Tuban. Jurnal RUAS, 15 (2). Pp 31-39.

Santri, T. (2018). Analisis Karakteristik Visual Arsitektur Pemukiman Nelayan, Studi Kasus: Desa Kalibuntu Probolinggo. Jurnal TIARSIE, 15(2).

Santri, T. Novis Putri, T. (2020). Genius Loci permukiman Nelayan Pantai Utara Tuban Jawa Timur, Studi Kausu Kelurahan Kingking dan Kelurahan Karangsari. Jurnal ARCADE, 4 (2). Pp 101-106.

Suprihardjo, R dan Rahmawati, D. (2014). Peran Masyarakat dan Permukiman Nelayan Sebagai Dasar Pengembangan Kawasan Minapolitan di Lamongan, studi kasus Permukiman Minapolis Brondong Lamongan. Jurnal Tesa Arsitektur. Vol XII (2). pp 129-140.

Tim Riset Pertemuan Arsitektur pantai Utara Jawa. (2008). Pertemuan Arsitektur pantai Utara Jawa: Cirebon, Tegal, Pekalongan, Semarang, Lasem, Tuban. Bandung: Cipta Sastra Salura. 